\title{
Approved nominations to affiliateship
}

It was agreed that the following should become Affiliates:

Dr A. M. Ahmad, Dr M. H. Ansari, Dr D.S.C. Attale, Dr K. R. Attaluri, Dr R. Balakumaran, Dr M. M. Bhanot, Dr A.G. Blower, Dr M.G.L. Bustos, Dr T. K. Chattopadhyay, Dr A. P. Desai, Dr B. M. Doherty, Dr B. L. Eckland, Dr A.D.A. Forti, Dr M. C. Gabbott, Dr I. M. Green, Dr D. V. Gold, Dr A. M. Gupte, Dr S. Hamid, Dr N. N. Hanna, Dr M. Hughes, Dr N. Jeganathan, Dr M.T. Khine, Dr J.P. Mahon, Dr S. K. Majumdar, Dr H. Y. Mohammed, Dr C. E. A. Montgomery, Dr C.L. Morrison, Dr Y.A. Morrison, Dr S.M. Mundasad, Dr K. K. Naing, Dr C. H. Nash, Dr V. Nathan, Dr E. A. O'Donnell, Dr J. P. Pandaraka- lam, Dr J. J. Patel, Dr S. C. Patel, Dr L. Paul, Dr J.J. Potts, Dr M. H. Radcliffe, Dr N.A. Rahman, Dr G. Rao, Dr A. J. Salih, Dr M. P. Shah, Dr H. M. Singh, Dr A. Sinorwala, Dr A. J. Soltysiak, Dr N. Srinivasan, Dr A. Stewart, Dr A. H. Szemis, Dr S. Tamarazians-Gharat-Chedaghi, Dr K. L. Thein, Dr S. M. Vaidya, Dr T. Vithana, Dr J.S. Welbourne, Dr T.S. Wong.

\section{Erratum - List of New Fellows}

We apologise for the incorrect spelling of $\operatorname{Dr} R$. W. Latcham in the list published in the July Bulletin.

\section{Council Report}

\section{Meeting the Mental Health Needs of People with Learning Disability}

\section{Part 1. Adults with mild learning disability. June 1996 Part 2. Elderly people with learning disability. April 1997}

\section{CR56. 41 pp. $£ 7.50$}

A report addressing the mental health needs of elderly people with learning disability was produced by a joint working group between the Section for the Psychiatry of Learning Disability and the Section for the Psychiatry of Old Age. This should be read in conjunction with the joint report between the Section for the Psychiatry of Learning Disability and the General Psychiatry section. The two reports are published jointly as Council Report CR56. 'Meeting the Mental Health Needs of People With Learning Disability'.

Part 2.

The lifespan of the population is increasing, and this is particularly true of people with learning disability, who can now expect to live to middle or old age. Due to the resettlement of people from National Health Service institutions this group now live in a wide range of residential settings in the community. Care staff in elderly services usually lack experience in learning disability and care staff in learning disability services usually lack experience in old age. Consequently care staff in either setting may not be equipped to recognise mental health needs in elderly people with learning disabilities when they arise.

The complexity and high prevalence rates of mental health needs (due to the additional risk factors associated with learning disabilities and the additional risk factors associated with old age) are such that a comprehensive provision of specialist mental health services is essential to meet the needs of this group.

The report emphasises the need for flexibility and collaboration between old age psychiatric services and learning disability psychiatric services, and discusses which service should take the lead in different cases. The report also highlights the need to audit and monitor service provision, particularly in view of the anticipated future increase in the number of elderly people with learning disability.

WORKING GROUP MEMBERS: Dr Sally-Ann Cooper, Consultant in Learning Disabilities Psychiatry, Dr Jane McCarthy, Consultant in Learning Disabilities Psychiatry, and Dr Daphne Wallace, Consultant in Old Age Psychiatry

Council Reports may be purchased at the College or by mail order. Further information and telephone orders: Lee Bartlett, The Royal College of Psychiatrists, 17 Belgrave Square, London SWIX 8PG (Tel: 01712352351 ext. 146). Cheques should be made payable to the Royal College of Psychiatrists. 